\title{
Irrigation Water Quality and Soil Structural Stability: A Perspective with Some New Insights
}

\author{
Pichu Rengasamy
}

School of Agriculture, Food and Wine, Prescott Building, Waite Campus, The University of Adelaide, Adelaide 5005 SA, Australia; pichu.rengasamy@adelaide.edu.au; Tel.: +61-8-8313-7418

Received: 13 April 2018; Accepted: 11 May 2018; Published: 14 May 2018

\begin{abstract}
The sustainability of irrigated agriculture depends on the quality of irrigation water used. The electrolyte concentration (EC) of irrigation water may lead to the accumulation of salts in the root zone layers and affect the physiological functions of the crop by osmotic and ion toxicity effects. Further, the cationic and anionic composition of the water may alter the exchangeable cation composition of the soil as well as its $\mathrm{pH}$. Because of the dominance of sodium salts in many sources of irrigation water, parameters related to sodium such as exchangeable sodium percentage (ESP) of soils and sodium adsorption ratio (SAR) of soil solutions have been commonly used to study the effects of sodium in irrigation water on soil structural stability. Quirk and Schofield's concept of 'threshold electrolyte concentration' (TEC) has shown the importance of electrolytes in preventing the effects of sodium on soil structure. Based on this concept, several models have been proposed to relate ESP or SAR with EC to predict the possible impacts of irrigation water on soil structural stability. However, many research reports indicate that this relationship varies with soils, and a given model is not suitable for all types of soils. Further, the effects of potassium and magnesium in the processes leading to clay dispersion are disregarded in these models. This essay analyses all the factors involved in the structural failure of soils with different cationic composition, identifies the defects in these TEC models, and re-defines TEC on the basis of new insights on dispersive and flocculating charges of soils. This review does not deal with EC effects on crops nor the role of contaminant ions not involved with soil structural stability.
\end{abstract}

Keywords: water quality; soil structure; threshold electrolyte concentration; zero point of dispersion

\section{Introduction}

Irrigation of soils is an important component of productive agriculture, particularly in regions where rainfall is not sufficient to provide enough water to be used by crops during their growth and yield cycles. Because of an increase in yield potential and economic benefits, areas of irrigated agriculture have been increasing since the beginning of agricultural civilization in ancient times. However, productivity of irrigated agriculture is low in many parts of the world because of the poor quality of irrigation water impacting soils and crops. Good quality water with low amounts of dissolved salts has been found to be beneficial when used in productive soils. However, with increasing salt concentration in the water, decreasing crop growth and yield have been observed. In hostile soils, other soil constraints can also add to the stress on crops.

Salinity of irrigation water may lead to the accumulation of salts in soil layers above a threshold level and impact on crops by osmotic and ion toxicity effects [1] While the total concentration of salts in irrigated soils relates to the osmotic effects, the ionic composition determines ion toxicity and/or plant nutritional disorders. Further, cationic and anionic composition of irrigation water alters the adsorbed ionic status of the charged sites on soil components and also $\mathrm{pH}$ of soil water. Sodium dominant saline water from sources such as groundwater or waste water is commonly used when supplies 
of good quality water are limited or non-existent. This leads to high levels of adsorbed sodium in soils and deterioration of soil structure, with reduced infiltration and water movement, poor soil tilth, inadequate aeration, waterlogging, and anoxic conditions [2,3].

As the level of soil sodicity, commonly estimated as exchangeable sodium percentage (ESP), increases, soil aggregate stability in water declines because of increased swelling and dispersion of clay particles. However, these effects of increasing ESP are altered by the presence of electrolytes in soil water. Quirk and Schofield [4], in their widely cited 'Landmark Paper' [5], proposed the concept of 'threshold electrolyte concentration' (TEC), which is the electrolyte concentration (EC) in soil water above which the physical properties of a soil at a given ESP are not affected by sodicity. Based on this principle, several models have been proposed (e.g., [6-12], among others) relating ESP and EC of soils to either clay dispersivity or changes in hydraulic conductivity, and identifying the TEC to maintain soil structural stability. In many instances, sodium adsorption ratio (SAR) of irrigation water or soil solution is used instead of ESP to determine sodicity. The observations by these researchers have clearly shown that TEC varies widely in relation to many soil factors, and is a unique value for a given soil. However, soil managers and environmental consultants still choose and follow one of these models, and decide the quality of water (based on SAR and EC values), and its suitability for irrigation to all the soils they are dealing with, irrespective of varying soil factors.

The aims of this essay are: (1) Outline the basics of soil structural stability in water and analyse the various soil factors involved in swelling and dispersive behaviour of soils in relation to cationic and anionic composition of soil water. (2) Identify the deficits in the models based on the threshold electrolyte concentration concept. (3) Propose possible modifications of the TEC concept based on new insights. (4) Articulate conclusions and suggest future studies that are needed. This essay does not deal with irrigation water quality in relation to 'salinity' effects on crops, although the author recognizes its importance in management decisions related to improved productivity of irrigated crops. Also, the role of toxic contaminants not involved in soil structural processes is not discussed.

\section{Soil Structural Stability in Water}

\subsection{Aggregation of Soil Particles and Water Stability of Aggregates}

Soil structure refers to the heterogeneous arrangement of soil particles bound together as aggregates of different sizes and the resultant formation of different sized pores and their continuity, enabling soil physical processes such as movement of water and air. Soil structural stability is the ability of these aggregates to retain this arrangement when exposed to various externally applied stresses [13]. Different sized aggregates form by the combination of clay, silt, sand, and other inorganic and organic materials linked by several bonding mechanisms. These aggregates within soil clods have been classified in a hierarchical order, mainly on the basis of their size, ranging from clay floccules, domains, clusters, micro aggregates, macro aggregates through to clods, although not all of these hierarchical orders exist in all soils [14]. Breakdown of larger aggregates into smaller ones occurs as a result of externally applied mechanical stress such as by tillage implements, when the applied energy exceeds the bonding strength of the particle linkage. However, on wetting, the strength of aggregates are weakened significantly leading to their breakdown, irrespective of the force of application of water.

On wetting, 'slaking' of soil clods can occur where macro aggregates are disintegrated into micro aggregates. This phenomenon does not always destroy soil structure but introduces different soil structural forms which may not necessarily affect soil physical conditions conducive for crop production. However, the swelling and eventual dispersion of clay particles from aggregates by the interaction of water molecules with clay surfaces destroys all the hierarchical orders and the soil structure is degraded significantly, affecting soil physical properties, as experienced in sodic soils [14]. Swelling and dispersive behaviour of sodic soils originate from the interaction of polar water molecules with electrical fields induced by positive and negative charges on soil particles, particularly soil colloids. While in polar solvents, the degree of slaking and dispersion depends on the dielectric constant of the 
solvent and ESP of soil aggregates, in relatively nonpolar solvents with very low dielectric constants, slaking and dispersion of soil aggregates does not occur, irrespective of their sodicity levels (Table 1). Similarly, aggregates of particles without any net surface charge (available for hydration reactions) do not slake or disperse in water. Chorom and Rengasamy [15] showed that a Na-smectite, when heated above $300^{\circ} \mathrm{C}$, did not swell or disperse due to the absence of hydration charge as a result of the covalent bonding of $\mathrm{Na}$ with the clay structure.

Table 1. Slaking and dispersion of Alfisol aggregates (2-4 mm) at two levels of sodicity in various solvents (after Rengasamy and Sumner [16]). ESP = exchangeable sodium percentage.

\begin{tabular}{cccccc}
\hline Solvent & $\begin{array}{c}\text { Dielectric Constant } \\
\text { at 25 }{ }^{\circ} \text { C }\end{array}$ & $\begin{array}{c}\text { Slaking \% } \\
\text { ESP 1 } \mathbf{~ m m}\end{array}$ & $\begin{array}{c}\text { Slaking \% }<\mathbf{~ m m} \\
\text { ESP 20 }\end{array}$ & $\begin{array}{c}\text { Dispersed Clay as \% } \\
\text { of Total Clay } \\
\text { ESP 1 }\end{array}$ & $\begin{array}{c}\text { Dispersed Clay as \% } \\
\text { of Total Clay } \\
\text { ESP 20 }\end{array}$ \\
\hline Water & 78.5 & 67 & 80 & 0 & 26 \\
Ethanol & 24.3 & 24 & 12 & 0 & 0 \\
Benzene & 2.3 & 0 & 0 & 0 & 0 \\
n-Hexane & 1.9 & 0 & 0 & 0 \\
\hline
\end{tabular}

\subsection{Processes Leading to Structural Changes on Wetting of Dry Aggregates}

The mechanisms proposed by soil scientists for clay swelling and dispersion based on the double layer DLVO (developed by Derjaguin, Landau, Verwey and Overbeek) theory [17] are mainly applicable to colloids in aqueous suspensions. This theory has been found to be unsatisfactory in clays with divalent cations, where diffuse double layer formation is restricted to stacking or aggregation of particles [18,19]. Further, it does not account for the forces due to different cations involved as counter ions, and also the crystalline swelling of divalent ion saturated clays in high electrolyte concentrations [20]. In dry soils, clays are confined within aggregates and not suspended in water. To understand the mechanisms of slaking and dispersion of soil aggregates, it is necessary to take into account all the processes that occur during initial wetting of dry aggregates that result in swelling in the first stage to the final stage of aggregate disintegration, leading to dispersion of soil clays when completely wet. The magnitude and direction of energy changes due to hydration of charged sites during wetting of an aggregate are illustrated schematically in Figure 1, and the following discussions are based on the reports by Rengasamy and Sumner [16] and Rengasamy et al. [21].

The energy involved in hydration reactions depends on the electrical charge available on soil particles. The net electrical charge depends on the type and amount of clay minerals, organic matter, and other inorganic constituents. Although the net charge can be calculated on the basis of the charge on the individual components, the charge available for hydration is altered because of the different types of bonding among these components [22]. For example, soil clays are complex intergrowths of different clay structures intimately associated with inorganic and organic molecules and biopolymers; as a result, they do not have the same charge characteristics as the pure clay mineral counterparts of the soil clay mineral identified by $\mathrm{X}$-ray diffraction methods. The layer charge of clay minerals contributed by isomorphous substitution may be large, but the charge available for hydration may be quite different. This occurs in illites where $\mathrm{K}$ is bound to layer charge by inner-sphere complexation and smectites with charge originating from tetrahedral substitution leading to inner-sphere complexation of cations, including $\mathrm{Na}[23,24]$. Inner-sphere complexation of cations or molecules involves covalent bonding by clays resulting in hydrophobicity, whereas outer-sphere complexation of cations involves ionic bonding (electrostatic attraction) facilitating hydration. 


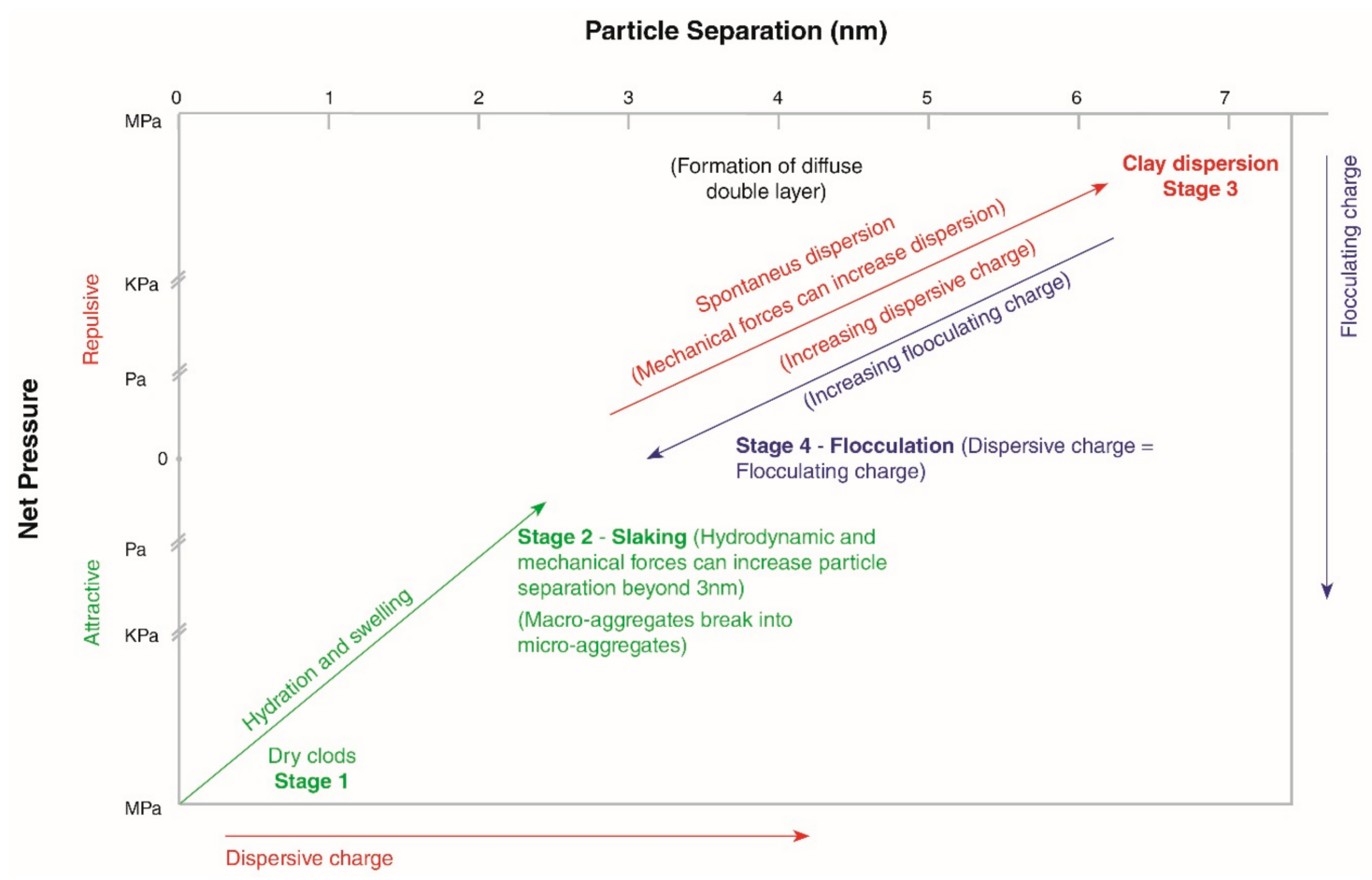

Figure 1. Particle separation from soil aggregates on wetting due to net pressure generated by dispersive and flocculating charges.

When a dry aggregate is wetted (stage 1 ; Figure 1), the initial attractive force between particles decreases significantly due to the repulsive hydration forces in the Mega Pascal (MPa) range. As the water content increases and hydration continues, the distance between the particles increases to $2-3 \mathrm{~nm}$, which is the stage of swelling (Figure 1) and the aggregate strength is reduced from MPa range to $\mathrm{kPa}$ (kilo Pascal) or Pa (Pascal) range. Although very weak, the net force is still attractive and the particles are held by hydrated cations. If these cations are divalent, further hydration is restricted because of the low ionicity of the clay-cation bonding [25]; the particles are not separated beyond 2-3 nm. Mg-clays swell more than Ca-clays [26,27], presumably because of higher ionicity of $\mathrm{Mg}$ bonds than Ca bonds. This 'crystalline swelling' of divalent cationic clays can occur even when soil water is highly saline, with macroscopic swelling being higher in low electrolyte concentrations [23]. Even though the particles are attracted with the net pressure in the kilo Pascal range, hydrostatic and pneumatic pressures in the range of kilo Pascal associated with pore filling are sufficient to break the weak linkage between particles, and the linked units become separated via a process which is known as 'aggregate slaking' (stage 2; Figure 1). The hypothesis that the mechanical stress due to the displacement of entrapped air during wetting or raindrop impact is the major reason for slaking is untenable. Unless the particle linkages are weakened by electrostatic interactions by polar water molecules, the low pressures associated with entrapped air or raindrop impact will fail to cause disintegration of aggregates, as observed in aggregates treated with non-polar solvents $[16,28]$.

As water content increases, extensive hydration of clays dominant in monovalent cations such as $\mathrm{Na}$ and $\mathrm{K}$ occurs. These monovalent cations are bonded to clays with higher ionicity compared to $\mathrm{Ca}$ and $\mathrm{Mg}$, and this leads to particle separation beyond $7 \mathrm{~nm}$. At this stage of clay dispersion (Stage 3, Figure 1), the particles are completely separated from each other and are not attracted to each other (i.e., not aggregated). This process, known as 'spontaneous dispersion', occurs because of macroscopic swelling with repulsive pressures of kilo Pascal magnitude.

The clay particles saturated by divalent ions ( $\mathrm{Ca}$ and $\mathrm{Mg}$ ) that have been separated by up to 2-3 nm by swelling pressures, can be pushed further apart by applying external mechanical pressure in the range of Pascal to kilo Pascal, such as occurs with shaking or raindrop impact. When they are 
separated beyond $7 \mathrm{~nm}$, the clay particles are dispersed with no attraction to each other, and this process is known as 'mechanical dispersion'. Ca or Mg clay aggregates can be dispersed when uniformly remoulded (i.e., with energy input) at or above critical water content, defined by Emerson [29] as the water content for dispersion. At lower water contents, attractive forces dominate in spite of the mechanical repulsive pressure introduced by remoulding. Dispersion will be enhanced by remoulding or mechanically shaking when the inorganic cements, such as calcium carbonate, surrounding the aggregate are broken. Similarly, mechanically broken bonds between clay and organic matter can act as peptizing agents, enhancing the ease of dispersion of soil [30]. In the field, tillage can cause this external mechanical pressure [12].

Dispersed clay particles come closer together when the difference in the chemical potential of water in inner and outer solutions approaches zero. As an example, when the $\mathrm{pH}$ of the clay suspension reaches the value of point of zero charge (PZC), the clays flocculate [31]. When soil water contains dissolved electrolytes, the electrostatic repulsive pressure is balanced by the increasing flocculating pressure, at which stage the components of attractive pressures such as Lifshitz-van der Waals forces become active. At this stage, flocculation or coagulation (used synonymously in soil science) occurs in clay or soil suspensions with high water content (Stage 4, Figure 1), and the 'flocculation value' in the suspension is termed the 'threshold electrolyte concentration'. On drying, the flocculated clay particles are increasingly attracted to each other; attractive pressures are far greater and depend on the bonding type of the cations. This association is termed as aggregation, or 'flocculation plus'. When soil water content is below saturation (or field capacity) and the electrolyte concentration is equal to or above the flocculation value, limited swelling of aggregates can occur. Extensive swelling and further dispersion on increasing the water content are prevented by the flocculating pressures (or flocculation powers) of the dissolved cations.

\subsection{Repulsive Forces in Relation to Cations and Anions}

The net electrical charge on soil particles is contributed by the type of associated clay minerals, inorganic materials, and organic matter. These charges are reduced when the components of an aggregate are linked by covalent bonding. According to thermodynamic principles, these charges have to be balanced by oppositely charged elements or molecules in order to be in a stable equilibrium. Generally, most agricultural soils (except perhaps some of Ferrosols, equivalent of Oxisols) have net negative charge, and the charges are balanced by exchangeable cations, most commonly by $\mathrm{Na}, \mathrm{K}, \mathrm{Mg}$, and $\mathrm{Ca}$. Exchangeable $\mathrm{Al}, \mathrm{Fe}$, and $\mathrm{Mn}$ can also be involved in acidic soils. While $\mathrm{Na}, \mathrm{K}, \mathrm{Mg}$, and $\mathrm{Ca}$ ions are hydrated (or solvated) by water molecules, $\mathrm{Al}, \mathrm{Fe}$, and $\mathrm{Mn}$ hydrolyse water molecules and form different positively charged hydroxy cations [32,33], which are usually bound to clays by covalent bonding. In soils with net positive charge (as in Oxisols), the charge is balanced by exchangeable anions, such as chloride, sulphate, and phosphate.

The bonds between exchangeable cations and clay particles (also clay-organic complexes) were thought to be completely ionic. However, recent advances in inorganic chemistry have shown that any given heteronuclear bond found in natural systems has a mixture of covalent and ionic character. Covalent bonding between a cation and an anion is favoured on the basis of their polarizability. Thus, the resultant ionicity or covalence of a cation bond with an anion will also be influenced by the nature of the anion. For example, the ionicity of $\mathrm{Ca}^{2+}$ in $\mathrm{CaCl}_{2}$ is higher than that in $\mathrm{CaCO}_{3}$. This is also reflected in their water solubility: $\mathrm{CaCl}_{2}$ being highly soluble compared to the very low solubility of $\mathrm{CaCO}_{3}$.

Marchuk and Rengasamy [25] hypothesized that, because of both increasing charge and increasing size of a clay particle, the electron cloud in the bond formation will be less influenced by the clay anion, and thus the covalency or ionicity index of a cation alone will indicate the ionic character of a clay-cation bond. These authors derived the covalency index (CI) of a clay-cation bond, which is defined by:

$$
C I=\left(I_{z} / I_{z+1}\right) Z^{0.5}
$$


where $Z$ is the valence of the cation whose ionization potential is $I_{z}$ and $I_{z+1}$ is the ionization potential when the valence of the cation changes to $Z+1$. Values of $C I$ are $\leq 1$.

The ionicity index (II) is then defined as II $=1-\mathrm{CI}$. The ionicity index of a clay-cation bond indicates the reactivity of water molecules disrupting the bond. Marchuk and Rengasamy [25] reported that the clay behaviour in aqueous suspensions such as turbidity (i.e., clay dispersion), zeta potential, or mean particle size of different homoionic soil clays, e.g., $\mathrm{Li}^{+}, \mathrm{Na}^{+}, \mathrm{K}^{+}, \mathrm{Mg}^{2+}, \mathrm{Ca}^{2+}, \mathrm{Sr}^{2+}$, or $\mathrm{Ba}^{2+}$, was highly correlated to their respective ionicity indices. Ionicity of clay-cation bonds determines the dispersive power of the adsorbed cations. It can be concluded that the inherent hydration charge of a soil is a result of the unique combination of its mineral and organic components as well as $\mathrm{pH}$, and is balanced by exchangeable cations, which is then altered by the degree of ionicity of clay-cation bonds.

\subsection{Net Dispersive Charge in Relation to Clay Dispersion}

The degree of ionicity of clay-cation bonding indicates water interaction, but swelling and dispersion depend on the dispersive power of cations [21]. These authors defined the 'dispersive charge' of a soil as:

$$
\text { Dispersive charge }=(\mathrm{Ca})+1.7(\mathrm{Mg})+25(\mathrm{~K})+45(\mathrm{Na})
$$

where concentrations of exchangeable cations measured at the given soil $\mathrm{pH}$ are expressed as $\mathrm{cmol}_{\mathrm{c}}$ $\mathrm{kg}^{-1}$ and the coefficients of each cation are their respective dispersive powers relative to Ca and are derived from the ionicity of clay-cation bonds.

The dispersive charge is reduced by the flocculating effects of cations present in electrolytes in soil solutions. Rengasamy et al. [21] also defined the 'flocculating charge' as follows in Equation (3):

$$
\text { Flocculating charge }=45(\mathrm{Ca})+27(\mathrm{Mg})+1.8(\mathrm{~K})+(\mathrm{Na})
$$

where the concentration of soluble cations in the dispersed (or flocculated) soil-water suspension is expressed as $\mathrm{cmol}_{\mathrm{c}} \mathrm{kg}^{-1}$ (on soil basis). The weighting factors of the cations are based on the flocculating powers of cations as discussed in Rengasamy and Sumner [16], and they are inversely proportional to the coefficients of the dispersive powers.

In dispersed suspensions, the 'net dispersive charge' (Dispersive charge - Flocculating charge) determines the amount of clay dispersed [21]. The Zeta potential of the dispersed clay is highly correlated with the net dispersive charge $[34,35]$ indicating the importance of electrostatic forces involved in clay dispersion and flocculation processes [36]. At zero point of dispersion (the point of complete flocculation), dispersive charge equals flocculating charge. Hence, threshold electrolyte concentration can be redefined as the flocculating charge at the point of zero dispersion.

\section{Deficits in the Models Based on Quirk-Schofield Concept on 'Threshold Electrolyte Concentration'}

In their Landmark paper, Quirk and Schofield [4] defined the threshold concentration of the electrolyte as the concentration that led to a $10-15 \%$ decrease of sodic soil permeability from its initial value measured at non-sodic conditions. In the absence of electrolytes, sodicity reduced the permeability to a great extent. This concept led to the practical application of electrolytes such as gypsum to combat the sodicity effects on soil physical conditions, and also to distinguish sodic (dispersive) soils from saline (flocculated) soils (Figure 2, where sodic soils are referred to as dispersive soils). The models published on the basis of this concept used ESP or SAR as parameters of sodicity and used EC (either as electrical conductivity or total cation concentration) for electrolyte concentration. Relating these two parameters to changes in hydraulic conductivity, TEC was derived as the point where the level of reduction in hydraulic conductivity was permissible for good plant functions. Some used clay dispersion-flocculation processes instead of changes in soil permeability (e.g., [12]). 


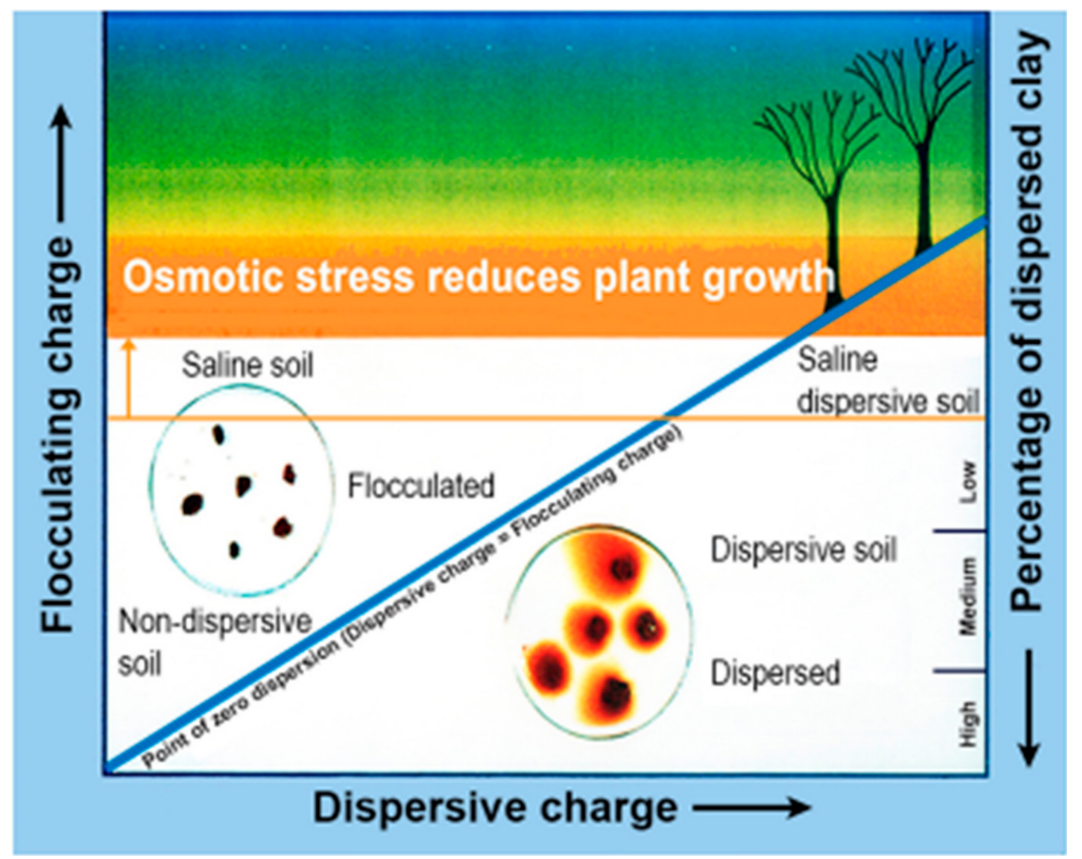

Figure 2. Distinction between saline and sodic (dispersive) soils based on dispersive charge, flocculating charge, and percentage of dispersed clay. (After Rengasamy [37], with permission from MDPI CC BY 4.0). Point of zero dispersion represents threshold electrolyte concentration (TEC).

It is now widely known that the TEC-SAR (or ESP) relationship is not universal, but unique for each soil. Several publications have revealed that many soil factors such as organic matter, clay content and mineralogy, cementing agents, and soil $\mathrm{pH}$ affect swelling, dispersion, and flocculation besides sodicity and salinity (e.g., [22,38-40]). For example, Blackmore [41] and McIntyre [42] have shown that 'subplastic' soils in Australia with an ESP of 25-30 do not disperse, and the hydraulic conductivity of these soils was independent of ESP. Because of cementation by several compounds including sesquioxides and carbonates, probably reducing the dispersive charge, these soils are not sensitive to increasing ESP. So and Aylmore [43] and Sumner [44] conclude that no simple definition of sodic soil based on a single ESP value is possible. Table 2 presents these soil factors and the mechanisms involved in controlling soil dispersive behaviour. Bennett and Raine [45], after experimenting with several soils, concluded that there are significant differences between TEC curves for soils with similar mineralogy, and even within the same soil type.

Thus, these models based only on measures of sodicity and EC are not sufficient to explain all soil dispersive behaviour. Further, these models do not take into account the roles of $\mathrm{K}$ and $\mathrm{Mg}$ in influencing clay dispersion. Several researchers have shown the dispersive effects of $K$ and also the less flocculating effect of Mg compared to Ca (e.g., [25,46]). The use of EC (either as electrical conductivity of soil solutions or as total cation concentration) instead of the concentration of individual cations in these models neglects the fact that clay flocculation depends on the individual flocculating power of the cations involved [21,47,48]. For example, a given concentration of calcium has about 45 times more flocculating power compared to the same concentration of $\mathrm{Na}$ (see Equation (3)). Another debate on the derivation of TEC centres is about how much reduction in permeability or clay dispersion is permissible for different soil textures $[7,38]$. 
Table 2. Soil factors controlling swelling, dispersion, and flocculation.

\begin{tabular}{ll}
\hline \multicolumn{1}{c}{ Soil Factors } & \multicolumn{1}{c}{ Mechanism } \\
\hline 1. Clay mineralogy and clay content & $\begin{array}{l}\text { Charge originates in clay structures because of isomorphous } \\
\text { substitution and broken bonds. Location of charge in the tetrahedral } \\
\text { structure is not available for hydration reactions. Thus, the total charge } \\
\text { depends on the mineralogy and the amount of clay in soils. }\end{array}$ \\
\hline 2. Soil pH & $\begin{array}{l}\text { Alters the charge on broken bonds by adsorption of } \mathrm{H}^{+} \text {or } \mathrm{OH}^{-} \text {ions. } \\
\text { With increasing concentration of carbonate anions, } \mathrm{pH} \text { increases, and } \\
\text { also negative charge on soil particles increases. When pH decreases, } \\
\text { as observed in acidic soils, negative charge decreases. }\end{array}$ \\
\hline 3. Organic matter & $\begin{array}{l}\text { Organic molecules bonded to clays by covalent bonding reduce the } \\
\text { hydration charge of clay particles. Unbound, charged organic } \\
\text { molecules can increase the hydration charge. Soil particles covered by } \\
\text { hydrophobic organic matter are not affected by water interaction. }\end{array}$ \\
\hline 4. Inner sphere complexes & $\begin{array}{l}\text { Cations such as Fe, Al, and K fixed by clay minerals by inner sphere } \\
\text { complexation (covalent bonding) reduce the hydration charge. }\end{array}$ \\
\hline 5. Cementation & $\begin{array}{l}\text { Cementation of soil particles by Fe and Al oxides or calcium carbonate } \\
\text { can block the charge available for water interaction. }\end{array}$ \\
\hline 6. Exchangeable cations & $\begin{array}{l}\text { Exchangeable cations are attached to charged soil particles by a mixture } \\
\text { of ionic and covalent bonding. The resultant ionicity of these bindings } \\
\text { determines the net hydration charge. Dispersive charge depends on the } \\
\text { dispersive power of the exchangeable cations. }\end{array}$ \\
\hline 7. Electrolytes & $\begin{array}{l}\text { Free (unbound) electrolytes in soil water contribute to the cationic } \\
\text { flocculating charge, which is a function of the flocculating power and } \\
\text { the concentration of individual cations. }\end{array}$ \\
\hline
\end{tabular}

\section{Modification of TEC Concept Based on New Insights}

\subsection{Use of Net Dispersive Charge to Explain Soil Structural Stability}

As discussed in earlier sections, the new concepts of dispersive charge, flocculating charge, and net dispersive charge lead to the re-definition of TEC as 'the flocculating charge estimated in flocculated soil suspensions (i.e., at the point of zero dispersion) where dispersive charge equals flocculating charge'. Determining these charges in a given soil eliminates the differences due to soil factors, detailed in Table 2. This new definition ends the current controversies reported in the literature on the effects of exchangeable cations, particularly $\mathrm{K}$ and $\mathrm{Mg}$, on soil structural stability [21]. Similarly, using the flocculating power of individual cations in determinations avoids the errors caused when electrical conductivity or total cation concentration is used to estimate TEC, where all the cations are considered to be equal in the flocculation process.

Because of the role played by soil $\mathrm{pH}$ in determining the charge on particles, it is necessary to estimate the exchangeable cations and soluble cations at a given soil $\mathrm{pH}$. However, it is very tedious to estimate exchangeable cations at a given soil $\mathrm{pH}$. However, by using 1:5 soil water suspensions in flocculation experiments to measure flocculating charge, soil $\mathrm{pH}$ can be maintained. The procedure is essentially similar to the determination of 'dispersive potential' as described by Rengasamy [47] and slightly modified by Marchuk and Rengasamy [48]. Known amounts of flocculants such as $\mathrm{CaCl}_{2}$ are added to the dispersed suspensions step by step until complete flocculation is achieved. From the amount of $\mathrm{CaCl}_{2}$ added and the concentrations of other cations in the original dispersed suspension, flocculating charge on a soil basis can be estimated by using the Equation (3) for flocculating charge. If the addition of flocculants alters the $\mathrm{pH}$ of the suspension, $\mathrm{pH}$ adjustment may be needed.

\subsection{Validity of Models Based on Irrigation Water Quality}

Some of the models (e.g., [6]) based on TEC use the parameters such as SAR and EC measured in irrigation water to predict the effects of application of irrigation water on soil structural behaviour. However, it is well known that the effects of irrigation water on soil permeability and the reactions of irrigation water with soils such as adsorption of cations and solubility of soil constituents are influenced by several soil factors. As noted earlier, the changes in soil chemical and physical properties 
after treatment with irrigation water of a given quality are unique to each soil. Therefore, it is necessary to analyse the soils irrigated with a given water quality or the soils equilibrated with that irrigation water, so that the impact of irrigation water on soil structural stability can be established.

Irrigation waters commonly resourced from groundwater contain $\mathrm{NaCl}$ as the predominant salt. Hence, in earlier research, parameters such as SAR and ESP were central to determining effects on soil structural behaviour. The SAR model, on the basis of the 'Ratio Law' of Schofield [49], was developed to predict the adsorption of $\mathrm{Na}$ from soil solutions by charged particles. SAR of soil solutions is correlated with the ESP of soils, but the relationship varies with many soil factors. However, it has been commonly used to relate to clay dispersion instead of ESP because measurement of ESP is tedious and laborious. SAR is defined as:

$$
\mathrm{SAR}=\mathrm{Na} /\left[(\mathrm{Ca}+\mathrm{Mg})^{0.5}\right]
$$

where concentrations of cations in soil solutions are expressed as $\mathrm{mmol} \mathrm{L}^{-1}$.

SAR does not include monovalent $\mathrm{K}$ and also treats $\mathrm{Mg}$ as equal to $\mathrm{Ca}$. However, recent use of waste waters and re-cycled waters have been shown to introduce significant amounts of $\mathrm{K}$ and $\mathrm{Mg}$ in addition to $\mathrm{Na}$, and as discussed earlier, $\mathrm{K}$ may influence soil structural stability, and $\mathrm{Mg}$ effects may be different to those of Ca (e.g., [50-52]). In view of this, Marchuk and Rengasamy [25] introduced a new index, the cation ratio for soil structural stability (CROSS) to relate to clay dispersion. CROSS takes into account the relative dispersive powers of $\mathrm{Na}$ and $\mathrm{K}$, and also the relative flocculating powers of $\mathrm{Mg}$ and $\mathrm{Ca}$. CROSS is defined as:

$$
\text { CROSS }=(\mathrm{Na}+0.56 \mathrm{~K}) /\left[(\mathrm{Ca}+0.6 \mathrm{Mg})^{0.5}\right]
$$

where concentrations of cations in soil solutions are expressed as $\mathrm{mmol} \mathrm{L}^{-1}$.

Both CROSS and SAR are empirical properties. Relationship between SAR or CROSS and exchangeable cations may vary because many soil factors, including $\mathrm{pH}$, affect exchange reactions, and hence, the dispersive charge. In spite of including $\mathrm{K}$ and $\mathrm{Mg}$ effects in the formula, the relationship between CROSS and clay dispersion or hydraulic conductivity, although stronger than SAR, has been found to vary with soil factors [47,52-54]. It is becoming clearer that clay dispersion in relation to CROSS depends on the dispersive charge of a given soil. The roles of clay mineralogy, organic matter, $\mathrm{pH}$, and other soil constituents in influencing the charge available for water interactions are integrated in the concept of dispersive charge. Rengasamy et al. [21], using several soil samples with alkaline $\mathrm{pH}$, have shown a significant correlation between dispersive charge of soils and CROSS of soil solutions. Further studies using various soil types are needed to investigate the CROSS-dispersive charge relationship and to develop CROSS based models as guidelines for structural stability of irrigated soils.

\section{Conclusions and Future Studies}

Classifying irrigation water in relation to the impact on soil structural stability only on the basis of its ionic composition is not realistic, because the characteristics of the soil used for irrigation are also critical in the effects. The new concept of net dispersive charge influencing the degree of clay dispersion dispels the controversies surrounding the use of SAR (ESP) or CROSS and EC of soil solutions to explain structural stability of irrigated soils. Similarly, the debate on how much reduction in hydraulic conductivity or clay dispersion is to be considered to derive TEC is avoided by defining TEC as the flocculating charge at the point of zero dispersion, which is an ideal condition for maintaining structural stability. The $\mathrm{pH}$ effect on dispersive charge is managed by measuring the flocculating charge in the soil-water suspensions at the given $\mathrm{pH}$ of the soil, thus avoiding the tedious determination of exchangeable cations.

As shown in Figure 2, when dispersive charge equals flocculating charge, clay dispersion is zero and physical properties of irrigated soils are not adversely affected. However, when the flocculating 
charge exceeds the threshold levels of crop tolerant salinity (measured as EC), crops are affected by osmotic stress and/or ionic toxicity. Then, the soil becomes a 'saline' soil, but not dispersive. However, when the flocculating charge is less than the dispersive charge, but at the same time the salt concentration is not tolerated by crops, the soil becomes 'saline-dispersive' with compounded effects of salinity and soil structural instability.

By conducting dispersion-flocculation experiments using a particular soil, the impact of irrigation water of known quality (in terms of composition of cations and anions) can be easily determined. If an irrigated soil remains flocculated, it indicates that the irrigation water contains cations at TEC levels and does not pose a threat to soil structure. However, the EC (salinity) effects on crops to be grown has to be determined for the successful use of that water. To avoid both these effects, the EC (due to $\mathrm{NaCl}$ ) of irrigation water can be lowered and cations with high flocculating charge such as $\mathrm{Ca}^{2+}$ can be introduced. If a dispersive soil is flocculated by $0.1 \mathrm{M} \mathrm{NaCl}$ of an EC of $10 \mathrm{dS} \mathrm{m}^{-1}$, then the same can be achieved by $0.0022 \mathrm{M} \mathrm{CaCl}_{2}$ with an $\mathrm{EC}$ of $0.22 \mathrm{dS} \mathrm{m}^{-1}$. An alternative option could be appropriate leaching of salt $(\mathrm{NaCl})$ in the field by improving the leaching fraction and adding calcium compounds to soil such as gypsum to maintain structural stability. $\mathrm{Ca}^{2+}$ from gypsum application can reduce dispersive charge by reducing the levels of exchangeable Na and $\mathrm{K}$, and also can increase the flocculating charge in soil solutions. This concept based on dispersive and flocculating charges can pave a way to identifying innovative measures to reduce the dispersive charge and increase the flocculating charge of structurally degraded irrigated soils.

Jenkins and Morand [55], experimenting on acid-sodic soils ( $\mathrm{pH}$ in water $<5.5)$ in New South Wales, Australia, concluded that relationships between clay dispersion, ESP, CEC (cation exchange capacity), and $\mathrm{Al}$ in these soils were complex and generally no trends were discernible. They also noted that ESP was a poor indicator of dispersive behaviour of acidic-sodic soils. In dispersive acidic soils, the role of $\mathrm{pH}, \mathrm{Al}$, and $\mathrm{Fe}$ bound to clays in reducing dispersive charge and also the flocculating effects of the ionic species of $\mathrm{Al}$ and $\mathrm{Fe}$ in soil solutions have not yet been investigated.

The current concept proposed in this essay has to be validated in all types of reclamation of salt-affected soils and in the application of poor quality irrigation water to soil. Laboratory determinations of TEC can serve only as guidelines for a soil irrigated with a specified water. Under field conditions, the chemical and physical effects of irrigation water can vary with several factors (e.g., [56-59]) such as drainage provisions, leaching fractions of soil layers, soil tillage conditions (cultivated vs no-tillage), and also methods of irrigation (flood irrigation, sprinkler, or drip irrigation). Combining all these factors in the models used for predicting the sustainability of irrigation will be necessary to arrive at a practical approach to mitigate irrigation water effects on soil structure. However, frequent soil monitoring in the field after irrigation in conjunction with the laboratory derived parameters and evaluating the crop response in the field, can be useful in the management of irrigated soils. These approaches will be particularly important in land application of coal seam water and various other waste and recycled waters which are being promoted globally.

Acknowledgments: The author thanks the Grain Research and Development Corporation of Australia for the financial support (GRDC project UA 00159) and Richard Greene of Australian National University whose comments improved the quality of this essay.

Conflicts of Interest: The author declares no conflict of interest.

\section{References}

1. Munns, R.; Tester, M. Mechanisms of salinity tolerance. Annu. Rev. Plant Biol. 2008, 59, 651-681. [CrossRef] [PubMed]

2. Oster, J.D.; Jayawardane, N.S. Agricultural management of sodic soils. In Sodic Soils: Distribution, Management and Environmental Consequences; Sumner, M.E., Naidu, R., Eds.; Oxford University Press: New York, NY, USA, 1998; pp. 125-147.

3. Rengasamy, P.; Olsson, K.A. Irrigation and sodicity. Aust. J. Soil Res. 1993, 31, 821-837. [CrossRef] 
4. Quirk, J.P.; Schofield, R.K. The effect of electrolyte concentration on soil permeability. Eur. J. Soil Sci. 1955, 6, 163-178. [CrossRef]

5. Rimmer, D.L.; Kirk, G.J.D.; Bourrie, G. Landmark papers: No.2. Commentary on the impact of Quirk \& Schofield (1955). Eur. J. Soil Sci. 2013, 64, 3-15.

6. Ayers, R.S.; Westcot, D.W. Water quality for agriculture. In FAO Irrigation and Drainage; Paper 29 (Rev.1); FAO: Rome, Italy, 1985.

7. De Menezes, H.R.; de Almeida, B.; Bennett, J.M.; da Silva, E.; Freire, M. Use of threshold electrolyte concentration analysis to determine salinity and sodicity limit of irrigation water. Rev. Bras. Eng. Agric. Ambient. 2014, 18, S53-S58. [CrossRef]

8. Essington, M.E. Soil and Water Chemistry: An Integrative Approach, 2nd ed.; CRC Press, Taylor and Francis Group: Boca Raton, FL, USA, 2015; 633p.

9. Ezlit, Y.; Bennett, J.M.; Raine, S.R.; Smith, R. Modification of the McNeal clay swelling model improves prediction of saturated hydraulic conductivity as a function of applied water quality. Soil Sci. Soc. Am. J. 2013, 77, 2149-2156. [CrossRef]

10. Jayawardane, N.S. An equivalent salt solutions method for predicting hydraulic conductivities of soils for different salt solutions. Aust. J. Soil Res. 1979, 17, 423-428. [CrossRef]

11. McNeal, B.L.; Coleman, N.T. Effects of solution composition on soil hydraulic conductivity. Soil Sci. Soc. Am. J. 1966, 30, 308-312. [CrossRef]

12. Rengasamy, P.; Greene, R.; Ford, G.W.; Mehanni, A.H. Identification of dispersive behaviour and the management of red-brown earths. Aust. J. Soil Res. 1984, 22, 413-431. [CrossRef]

13. Amezketa, E. Soil aggregate stability: A Review. J. Sustain. Agric. 1999, 14, 83-151. [CrossRef]

14. Dexter, A.R. Advances in characterization of soil structure. Soil Tillage Res. 1988, 11, 199-238. [CrossRef]

15. Chorom, M.; Rengasamy, P. Effect of heating on swelling and dispersion of different cationic forms of a smectite. Clays Clay Miner. 1996, 44, 783-790. [CrossRef]

16. Rengasamy, P.; Sumner, M.E. Processes Involved in Sodic Behaviour. In Sodic Soils: Distribution, Management and Environmental Consequences; Sumner, M.E., Naidu, R., Eds.; Oxford University Press: New York, NY, USA, 1998; pp. 35-50.

17. Van Olphen, H. An Introduction to Clay Colloid Chemistry, 2nd ed.; John Wiley: New York, NY, USA, 1977.

18. Greene, R.S.B.; Posner, A.M.; Quirk, J.P. Factors affecting the formation of quasi-crystals of montmorillonite. Soil Sci. Soc. Am. J. 1973, 37, 457-460. [CrossRef]

19. Swartzen-Allen, S.L.; Matijevic, E. Surface and colloid chemistry of clays. Chem. Rev. 1974, 74, 385-400. [CrossRef]

20. Kjellander, R.; Marcelja, S.; Quirk, J.P. Attractive double-layer interactions between calcium clay particles. J. Colloid Interface Sci. 1988, 126, 194-211. [CrossRef]

21. Rengasamy, P.; Tavakkoli, E.; McDonald, G.K. Exchangeable cations and clay dispersion: Net dispersive charge, a new concept for dispersive soil. Eur. J. Soil Sci. 2016, 67, 659-665. [CrossRef]

22. Rengasamy, P.; Olsson, K.A. Sodicity and soil structure. Aust. J. Soil Res. 1991, 29, 935-952. [CrossRef]

23. Slade, P.G.; Quirk, J.P.; Norrish, K. Crystalline swelling of smectite samples in concentrated NaCl solutions in relation to layer charge. Clays Clay Miner. 1991, 39, 234-238. [CrossRef]

24. Sposito, G.; Skipper, N.T.; Sutton, R.; Park, S.; Soper, A.K.; Greathouse, J.A. Surface geochemistry of the clay minerals. Proc. Natl. Acad. Sci. USA 1999, 96, 3358-3364. [CrossRef] [PubMed]

25. Marchuk, A.; Rengasamy, P. Clay behaviour in suspension is related to the ionicity of clay-cation bonds. Appl. Clay Sci. 2011, 53, 754-759. [CrossRef]

26. Laird, D.A. Influence of layer charge on swelling of smectites. Appl. Clay Sci. 2006, 34, 74-87. [CrossRef]

27. Norrish, K. The swelling of montmorillonite. Trans. Faraday Soc. 1954, 18, 120-134. [CrossRef]

28. Hu, F.; Liu, J.; Xu, C.; Wang, Z.; Liu, G.; Li, H.; Zhao, S. Soil internal forces initiate aggregate breakdown and splash erosion. Geoderma 2018, 320, 43-51. [CrossRef]

29. Emerson, W.W. Inter-particle bonding. In Soils: An Australian Viewpoint; Academic Press: London, UK, 1983; pp. 477-498.

30. Emerson, W.W. Emerson Dispersion Test. In Soil Physical Measurement and Interpretation for Land Evaluation; McKenzie, N., Coughlan, K., Cresswell, K., Eds.; CSIRO Publishing: Collingwood, Australia, 2002; pp. 190-199.

31. Chorom, M.; Rengasamy, P.; Murray, R.S. Clay dispersion as influenced by $\mathrm{pH}$ and net particle charge of sodic soils. Aust. J. Soil Res. 1994, 32, 1243-1252. [CrossRef] 
32. Brady, N.C.; Weil, R.R. The Nature and Properties of Soils; Pearson Education, Inc.: Upper Saddle River, NJ, USA, 2008.

33. Rengasamy, P.; Oades, J.M. Interaction of monomeric and polymeric species of metal ions with clay surfaces. IV. Mixed system of aluminium (III) and iron (III). Aust. J. Soil Res. 1979, 17, 141-153. [CrossRef]

34. Chorom, M.; Rengasamy, P. Dispersion and zeta potential of pure clays as related to net particle charge under varying pH, electrolyte concentration and cation type. Eur. J. Soil Sci. 1995, 46, 657-665. [CrossRef]

35. Marchuk, A.; Rengasamy, P.; McNeill, A. Influence of organic matter, clay mineralogy, and pH on the effects of CROSS on soil structure is related to the zeta potential of the dispersed clay. Soil Res. 2013, 51, 34-40. [CrossRef]

36. Wilson, M.J.; Wilson, L.; Patey, I. The influence of individual clay minerals on formation damage of reservoir sandstones: A critical review with some new insights. Clay Miner. 2014, 49, 147-164. [CrossRef]

37. Rengasamy, P. Soil chemistry factors confounding crop salinity tolerance-A Review. Agronomy 2016, 6, 53. [CrossRef]

38. Dang, A.; Bennett, J.M.; Marchuk, A.; Biggs, A.; Raine, S.R. Quantifying the aggregation-dispersion boundary condition in terms of saturated hydraulic conductivity reduction and the threshold electrolyte concentration. Agric. Water Manag. 2018, 203, 172-178. [CrossRef]

39. Quirk, J.P. The significance of the threshold and turbidity concentrations in relation to sodicity and microstructure. Aust. J. Soil Res. 2001, 39, 1185-1217. [CrossRef]

40. Sumner, M.E.; Rengasamy, P.; Naidu, R. Sodic soils: A reappraisal. In Sodic Soils: Distribution, Management and Environmental Consequences; Sumner, M.E., Naidu, R., Eds.; Oxford University Press: New York, NY, USA, 1998; pp. 3-17.

41. Blackmore, A.V. Subplasticity in Australian soil. IV. Plasticity and structure related to clay cementation. Aust. J. Soil Res. 1976, 14, 261-272. [CrossRef]

42. McIntyre, D.S. Exchangeable Na, subplasticity and hydraulic conductivity of some Australian soils. Aust. J. Soil Res. 1979, 17, 115-120. [CrossRef]

43. So, H.B.; Aylmore, L.A.G. How do sodic soils behave-The effects of sodicity on soil physical behaviour? Aust. J. Soil Res. 1993, 31, 761-777. [CrossRef]

44. Sumner, M.E. Sodic soils-New perspectives. Aust. J. Soil Res. 1993, 31, 683-750. [CrossRef]

45. Bennett, J.M.; Raine, S.R. The soil specific nature of threshold electrolyte concentration analysis. In Proceedings of the 5th Joint Australian and New Zealand Soil Conference, Hobart, Australia, 2-7 December 2012; pp. 302-305.

46. Smiles, D.; Smith, C. A survey of the cation content of piggery effluents and some consequences of their use to irrigate soil. Aust. J. Soil Res. 2004, 42, 231-246. [CrossRef]

47. Marchuk, A.; Rengasamy, P. Threshold electrolyte concentration and dispersive potential in relation to CROSS in dispersive soils. Soil Res. 2012, 50, 473-481. [CrossRef]

48. Rengasamy, P. Clay Dispersion. In Soil Physical Measurement and Interpretation for Land Evaluation; McKenzie, N.J., Coughlan, K., Cresswell, H., Eds.; CSIRO Publishing: Collingwood, Australia, 2002; Chapter 14; pp. 200-210.

49. Schofield, R.K. A ratio law governing the equilibrium of cations in soil solutions. In Proceedings of the 11th International Congress of Pure and Applied Chemistry, London, UK; 1947; Volume 3, pp. 257-261.

50. Arienzo, M.; Christen, E.W.; Jayawardane, N.S.; Quayle, W.C. The relative effects of Na and K on soil hydraulic conductivity and implications for winery wastewater management. Geoderma 2012, 173-174, 303-310. [CrossRef]

51. Buelow, M.C.; Steenwerth, K.; Parikh, S.J. The effect of mineral-ion interactions on soil hydraulic conductivity. Agric. Water Manag. 2015, 152, 777-785. [CrossRef]

52. Oster, J.D.; Sposito, G.; Smith, C.J. Accounting for potassium and magnesium in irrigation water quality assessment. Calif. Agric. 2016, 70, 71-76. [CrossRef]

53. Farahani, E.; Emami, H.; Keller, T. Impact of monovalent cations on soil structure. Part II. Results of two Swiss soils. Int. Agrophysics 2018, 32, 69-80. [CrossRef]

54. Jayawardane, N.S.; Christen, E.W.; Arienzo, M.; Quayle, W.C. Evaluation of the effects of cation combinations on soil hydraulic conductivity. Soil Res. 2011, 49, 56-64. [CrossRef]

55. Jenkins, B.; Morand, D. An overview of acid-sodic soils in two regions of New South Wales, Australia. In Proceedings of the 3rd Australian New Zealand Soils Conference (SuperSoil 2004), Sydney, Australia, 5-9 December 2004. 
56. Apesteguia, M.; Virto, I.; Orcary, L.; Bescansa, P.; Enrique, A.; Imaz, M.J.; Karlen, D.L. Tillage effects on soil quality after three years of irrigation in northern Spain. Sustainability 2017, 9, 1476. [CrossRef]

57. Bower, C.A.; Ogata, G.; Tucker, J.M. Root zone soil profiles and alfalfa growth as influenced by irrigation water salinity and leaching fraction. Agron. J. 1969, 61, 783-785. [CrossRef]

58. Mmolawa, K.; Or, D. Root zone solute dynamics under drip irrigation: A review. Plant Soil 2000, 222, 163-190. [CrossRef]

59. Prendergast, J.B. A model of crop yield response to irrigation water salinity: Theory, testing and application. Irrig. Sci. 1993, 13, 157-164. [CrossRef]

(C) 2018 by the author. Licensee MDPI, Basel, Switzerland. This article is an open access article distributed under the terms and conditions of the Creative Commons Attribution (CC BY) license (http://creativecommons.org/licenses/by/4.0/). 